\title{
Bilateral Positioning Model for the E-commerce Platform
}

\author{
Xiaotong Du ${ }^{1,}$ a Rui Guo ${ }^{2, b}$ and Lingyi Xiao ${ }^{3, \mathrm{c}}$ \\ ${ }^{1}$ Northeast Normal University, China \\ ${ }^{2}$ Northeast Normal University, China \\ ${ }^{3}$ Northeast Normal University, China

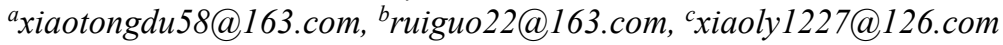 \\ The three authors contribute equally and are listed in alphabetical order.
}

\begin{abstract}
As the link between consumers and merchants, e-commerce platforms have problems that need to be improved. In particular, the accuracy and authenticity of the information they provide cannot be guaranteed, which will harm market fairness and consumers' right to know. To improve the presence of the e-commerce platform, the C2B model and big data are used, optimizing the consumer shopping experience and helping businesses to develop in the direction of professionalism. Based on this research concept, this article uses the systematic literature research method and collects professional literature through the search of keywords such as $\mathrm{C} 2 \mathrm{~B}$, e-commerce platform, big data, and supply chain. The article summarizes the findings of the literature and finds imperfections, thereby innovating the Bilateral Positioning Model, which is, respectively optimizing the UI interface of the merchant and the consumer, and embedding the supervision module so that consumer evaluation can play an important role in the healthy competition of the platform. While describing the Bilateral Positioning Model, this article also analyzes its feasibility and practicability and theoretically proves the sustainability of the model.
\end{abstract}

Keywords: C2B model, Supply Chain Improvement, Big Data, E-Commerce.

\section{INTRODUCTION}

\subsection{Background}

In order to understand consumers' perception of the operation of existing e-commerce platforms, the team conducted 140 questionnaire surveys and conducted a face-to-face online interview with the merchant on the e-commerce platform. More than a hundred survey reports and interview results show that consumers are generally dissatisfied with the platform's existing product screening system and quality assurance, so they will not make second purchases on this e-commerce platform. It can be seen that the existing e-commerce platforms have the fatal shortcomings of asymmetry between production and marketing information as well as chaotic management, which leads to the loss of customers However, with the development of Internet technology and logistics systems, e-commerce has gradually occupied an important position in modern human life [1]. Therefore, improving the e-commerce platform has become a common demand of consumers and businesses, which is also an urgent need for social and economic development.

\subsection{Our Work}

The team used a systematic literature review method to propose a Bilateral Positioning Model from the perspective of the $\mathrm{C} 2 \mathrm{~B}$ model, which structurally improved the supply system and the supervision system from both the demand side and the supply side. 


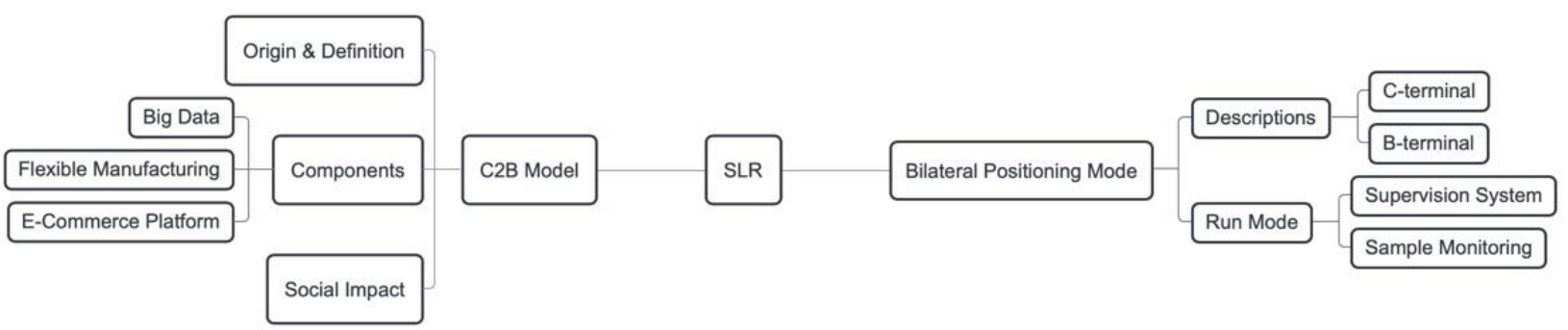

Figure 1 - The Structure of the Report

\section{THE SYSTEMATIC LITERATURE REVIEW OF THE C2B MODEL}

\subsection{The Origin and Definition of the C2B Model}

In recent years, with the birth of differentiated manufacturing, customized production, and other concepts, customer needs and ideas further affect the supply chain and accelerate the reform of the business model. In this transformation, enterprises pay more attention to the mode of production. Driven by customer demand, they produce multi-variety, small-batch, and personalized products, that is, they shift from the traditional inventory sales model to the reverse customization model for customers. This is the focus of this paper -- the $\mathrm{C} 2 \mathrm{~B}$ pattern [2]. The C2B model emphasizes the optimization of the supply chain and the role of customers during the process of improvement of the supply chain. It encourages companies to invest a certain amount of capital into customer insight and developing appropriate response strategies, which can help enterprises gain more competitive advantages, promote the popularization of the $\mathrm{C} 2 \mathrm{~B}$ model and its long-term operation.

C2B (Customer to Business) model, is a model for customizing production according to the needs of the consumers [3]. The concept of $\mathrm{C} 2 \mathrm{~B}$ originate from e-commerce and is based on Mass Customization and Mass Personalization, which can be defined respectively as C2B2M-MC (Customer to Business to ManufactoryMass Customization) mode and C2B2M-MP (Customer to Business to Manufactory- Mass Personalization) mode [2]. The $\mathrm{C} 2 \mathrm{~B}$ model relies on the Industrial Internet Platform to complete the transition from the traditional inventory model to the manufacturing mode, depending on the degree of user's personalized demand for the product [2].

\subsection{The Components of the C2B Model}

In the development of the $\mathrm{C} 2 \mathrm{~B}$ model, customers are increasingly involved in the construction process of the supply chain and have a profound impact on the production model of manufacturers. More and more companies are focusing on enhancing the customers' experience and gathering more customers' information.
The participation of customers improves the efficiency and accuracy of the supply chain, enabling enterprises to develop in the direction expected by customers in a targeted and accurate manner. At the same time, it also defines the future development direction according to the expectations of customers [4]. In this process, Big Data, Flexible Manufacturing Technology, and E-Commerce Platform are indispensable elements to make the $\mathrm{C} 2 \mathrm{~B}$ model run smoothly.

\subsubsection{Big Data}

Big Data has been widely used in major e-commerce platforms to process orders and recommend goods to customers. According to a survey of 273 customers, information search, recommendation system, dynamic pricing, and customer service based on big data operation have a significant positive impact on customer response and will play an essential role in developing a sustainable consumer market [5]. Big Data Analysis spawned tools such as user modeling and CTR (Click-through Rate) to understand customers better and recommend the right products to customers. User modeling first appeared in 1999. During the year, Alan Cooper wrote a book on interaction design, which brought significant attention to the necessity of role modeling mentioned therein [6]. Later, user modeling was adopted by the market and later by the marketing personnel, who modeled the "buyer" role through big data to better understand their market and recommend goods more suitable for users [7]. As an essential tool, CTR can judge whether online advertising is effective. Search engine advertising has become the main form of online advertising at present. Haans has studied the effective way to judge different types of data with CTR, thus obtaining different data types that are most suitable for analyzing different kinds of customers, which helps e-commerce platforms to recommend personalized goods more accurately [8].

Different from offline, online shopping in which customer comments are very influential, it is necessary to analyze the evaluation through big data. In e-commerce platforms, self-created content such as comments left by customers is also called user-generated content (UGC), which helps understand customers' shopping experience and influence future customers' purchase intentions [9]. Based on online customer text reviews, one research uses 
the method of text mining-latent semantic analysis (LSA), which combines the concept of product attributes with customers' online text reviews and customers' views, thus helping business managers to better understand customers' needs through user-generated content [9]. There is more and more competition in e-commerce, and many businesses' behavior of self-criticism can be identified through data processing. For example, context embedding with fewer nonverbal clues, argument structure, and flattering comments will cause customers to perceive the comments as deceptive. Therefore, the data can identify and record the sellers and buyers who violate the rules [10]. Through big data analysis, comments can deepen the understanding of customers and prevent cheating from sellers and regulate the market.

Countless researches on the application of big data on e-commerce platforms have found that e-commerce platforms mainly use big data to analyze customers, while there is less application of big data processing for merchants. The Bilateral Positioning Model can make up for the lack of big data for merchants on the current platform. After big data analysis, information such as sellers' credit will be open and transparent. The buyer can select the right commodity efficiently and select the right seller, thus taking more initiative in the $\mathrm{C} 2 \mathrm{~B}$ model.

\subsubsection{Flexible Manufacturing Technology}

With the development of Internet and logistics technology as well as personalized consumption, the production model of enterprises has begun to shift to being driven by customer orders [11]. Moreover, the rapid rise of e-commerce has forced manufacturers to consider their production processes and seek more efficient and timely technologies [12]. However, this transformation also requires the support and integration of new technologies. For instance, flexible manufacturing technology (commonly known as lean production) is designed to save setup time, increase machine utilization, and improve quality control [13]. Flexible manufacturing technology can achieve mass customization, that is, the ability to simultaneously achieve two goals that were once considered incompatible: low cost and product customization [13]. Flexible manufacturing technology enables manufacturers to produce multiple models at low cost and high efficiency, thereby prompting companies to customize products for the needs of small consumer groups [13]. And the cost required for flexible production can be achieved only by mass production of standardized commodities, which is able to improve the responsiveness of its customers [13]. Therefore, the Bilateral Positioning Model advocates on the supplier side that production companies stationed on the e-commerce platform adopt flexible production technologies to reduce physical expenditures, such as reducing shop rent, ground rent, labor costs, etc., to gain the price competitive advantage of online companies, thereby expanding the trading market and customer groups. In addition, the function of comprehensive evaluation and competitive advantage ranking proposed by the Bilateral Positioning Model for online sales manufacturers also require them to use flexible production technology to "private customization" for customers, and to cultivate the corporate unique competitive advantage and product attractiveness, so as to obtain the ideal ranking on the platform.

Quality control is another major goal of lean production [13], which can be combined with total quality management (TQM). The main steps of TQM are positioned to increase profitability in terms of manufacturing (increasing productivity and reducing error rates) and service (high-quality warranty from employees) aspects [13]. Its modern application is Six Sigma, that is, the accuracy of the production process is 99.99966\% [13]. The strict supervision system of the Bilateral Positioning Model takes effective and authentic feedback from customers as a cornerstone, and therefore puts forward higher quality requirements for manufacturers on the e-commerce platform. E-commerce companies should strictly monitor product quality to reduce the incompleteness of products and customer dissatisfaction, so as to obtain long-term development opportunities under the supervision of the Bilateral Positioning Model used by the e-commerce platform. The mutual cooperation between the Bilateral Positioning Model adopted by the e-commerce platform and the lean production employed by the corporation will vigorously promote the formation of a virtuous circle with the praise of customers and the expansion of the company's sales, so as to realize the precise connection of supply and demand.

\subsubsection{E-Commerce Platform}

Under the multi-agent system structure, the dynamic integration problems have been solved by business process reorganizations in the early development of e-commerce. Thus laying the foundation for the flexibility and intelligence of the e-commerce platform [14]. The innovation provides the possibility of a new model. Research has found that in China's online motion picture industry, platform choice can affect supplier efficiency [15]. Mature e-commerce platforms can promote the improvement of corporate efficiency by providing business infrastructure. This can be extended to other industries, especially for small and medium-sized enterprises that lack resources such as capital and capability of logistics. Its research prospect is to improve the governance rules of e-commerce platforms, such as quality, trust, and privacy [15]. By allowing consumers to participate in the upgrade process of corporate business, the platform can give full play to its role as a link, allowing consumer evaluation and platform selection to 
jointly affect corporate efficiency, and at the same time solve the problem of asymmetric information in the supply chain [16], to help businesses contact more target consumers. The description of the Bilateral Positioning Model shows that the supervision system in this model is essentially an incentive measure and compatible. However, another view about information asymmetry cannot be ignored: if a merchant joins a platform-initiated promotion, such as pre-sales, it will affect consumer psychology, and consumers are willing to purchase more or pay a premium through discounts or limited sales [17]. In general, the platform should have a complete supervision system, and reasonable sales methods within the system can benefit both consumers and businesses. The description of the Bilateral Positioning Model also reflects a breakthrough in the business management system. The platform is a link and a boost to promote the virtuous circle of e-commerce.

\subsection{The Impact of C2B model}

The customer insights advantage hypothesis says that "Resource advantage in customer information assets and customer information analysis capabilities, through their positive effects on customer insights, will have a positive effect on firm performance" [18]. In a market environment rich in Internet support, interaction, and digital data, such an impact will be even stronger [18]. In the Bilateral Positioning Model proposed, the team makes full use of the idea of this hypothesis to deepen the analysis insight of the client as much as possible and make it have an impact on the B end and even the whole supply chain. In today's interactive digital marketplace environment, companies have the ability and necessity to generate customer insights about individual customers in real-time, integrating them with accumulated insights to form detailed customer profiles [18]. Then small batch production, personalized customization, and personalized marketing for customers in segmented markets can be formed [18]. In this way, higher customer satisfaction can be achieved and higher efficiency and more value can be created.

To improve market performance, a firm must first know what major customers desire and actions its competitor takes, as well as the overall tendency of the industry. Through continuous access to customer information and market changes, enterprises can constantly improve their strategies and form a unique competitive advantage over their competitors. To make full use of the advantages of $\mathrm{C}$ end, $\mathrm{B}$ end enterprises need to constantly adjust their strategy to keep in line with customer value [19]. The suitability of strategic orientation is defined in terms of its fit, matching, or consistency with the environment or organizational contingencies faced by the enterprise [20]. Highly coordinated strategic measures can make enterprises gain stronger competitiveness. In the long run, the strategic alliance formed by the combination of enterprise strategy and customer value is not static but needs to adapt and develop dynamically over time [20]. This is also one of the innovation points of our model: the whole system is in a dynamic state of continuous development, to gradually improve the fit between $\mathrm{C}$ end and $\mathrm{B}$ end, and finally reach a virtuous cycle state.

\section{THE BILATERAL POSITIONING MODEL}

\subsection{Overview of the Model}

"Bilateral Positioning Model" is based on C2B and takes e-commerce platform as the carrier. It uses big data to clearly specify supply and demand and match merchants and consumers. At the same time, it sets up a supervision system and monitors sample changes to ensure the interaction among merchants, consumers and the platform, forming a virtuous cycle and ensuring the accuracy and authenticity of data.

\subsection{Description of C-terminal}

Based on the use of major e-commerce platforms in China and the rest world, our team found that most e-commerce platforms only provide categories such as price range when searching for goods to help consumers find goods without positioning for consumers' purchase as a whole. On this basis, the team's innovative "Bilateral Positioning Model" increases consumers' overall purchase propensity.

In the "Bilateral Positioning Model", the positioning of the $\mathrm{C}$ end, i.e., the positioning of the customer end, is mainly realized by the customer self-positioning and the platform with big data aid, which is also a positioning at the beginning and during the purchase process. When the customer enters the e-commerce platform, the customer can decide to view the commodity's attributes by setting the place of shipment, price range, and other aspects according to the customer's own needs for the product. Moreover, the e-commerce platforms will allow customers to set their preferences when entering the platform for the first time, such as high-cost performance, trendy niche, high quality but low price.

The two kinds of customer positioning are not static but not fixed. After becoming a customer, customers may change their minds as their income and purchasing power increase. The platform also provides an interface to change their positioning at any time. Although customers will initially choose price first or quality first as the basis for the platform to display goods, customers can change their positioning on the platform at any time. If consumers forget to change their position, customers will not receive the same product recommendation all the time. The platform collects customers' usual buying habits and consumers' data for a personalized recommendation, 
ensuring that consumers will receive recommendations that change consumers' consumption habits.

Major e-commerce platforms have basically built personalized recommendation systems, which has become one of the essential tools for powerful e-commerce platforms to provide consumers with a personalized shopping experience. It is the consensus for all e-commerce platforms that analyzing historical data is crucial to obtain customers' preferences, thus offering tailored website suggestions. Through a personalized recommendation system, e-commerce can improve consumers' conversion rate and improve the satisfaction and loyalty of consumers [21]. In the recommendation system, the platform calculates CTR through big data. The CTR of recommended products can be calculated through big data and compared with a typical click-through rate: if the CTR is bigger than $0.2 \%$, the recommendation is more effective [22]. The platform can find personalized recommendations suitable for consumers through CTR value. C-terminal positioning can help e-commerce platforms combine personalized recommendation systems to push products ideal for consumers and save their time in comparison. Consumers will buy more products when they see more products that meet their personal purchase wishes on the page, which also improves the profit and platform activity of the e-commerce platform.

In the e-commerce platform under $\mathrm{C} 2 \mathrm{~B}$ model, consumers enjoy more independent rights in $\mathrm{C}$-terminal positioning. E-commerce platforms can carry out user portrait through data of commodity types searched, browsed and purchased by consumers at ordinary times [23]. According to different consumer profiles, e-commerce platforms should recommend different commodities [23]. Consumers can change their personal consumption position on the e-commerce platform, whether they start using it or have been using it for some time. The platform provides the opportunity of changing interfaces and options. Simultaneously, in order for consumers to choose their products efficiently, the platform will also use big data to form a personalized recommendation system for a personalized recommendation. In the "Bilateral Positioning Model", the positioning of customers ensures the consumers' adequate autonomy in the $\mathrm{C} 2 \mathrm{~B}$ model, enables consumers to buy desired goods efficiently, and enables e-commerce platforms and merchants to make profits efficiently.

\subsection{Description of B-terminal}

The existing e-commerce platform already has the situation of business classification, but most of them are sorted according to some simple and solidified aspects, such as the price, brand, sales volume, etc. Although it can give consumers a certain classification of demand reference, but its lack of integrity and liquidity are easy to cause ranking solidification and bring unsatisfied shopping experience. A single sort can not fully reflect the characteristics and advantages of its corresponding businesses. At the same time, it will lead businesses showed on the platform to unilaterally pursue the improvement of one aspect and ignore the others, which is likely to cause them to sell goods whose quality of other aspects cannot be guaranteed. In addition, the long-term use of the same period of data will reduce the liquidity of business ranking, which is easy to cause businesses to bribe and vicious competition.

The "Bilateral Positioning Model" proposed in this project focuses on promoting the multidimensional ranking of businesses and the quantification of their scoring system, to reduce the intervention of human subjective factors and form an objective and systematic classification system. The performance evaluation under this model includes two aspects: horizontal and vertical. Horizontal direction is peer comparison, and vertical direction is self-positioning of merchants. Peer comparison takes the core competitiveness as the reference quantity, sorts and displays the core competitiveness of merchants and provides the advantages and disadvantages of merchants compared with other merchants, thus giving merchants a ranking position; On the other hand, the vertical aspect is based on the sampling inspection and investigation of platform science, which evaluates the scores of different categories of goods, implements the cumulative percentile ranking, evaluates the comprehensive level of stores by weighting and quantifying, and divides stores into different grades, so as to promote businesses to learn from each other's strengths and improve themselves. In addition, the platform will set up a separate data detection department to update all companies' operational data and samples to check their information's authenticity. The platform will have a corresponding reward and punishment mechanism for businesses who expose fraud and who provide false data to ensure the smooth operation of this mode.

\subsection{Supervision System}

The supervision system and real-time sample monitoring ensure the authenticity and accuracy of the data, which is the driving force for the self-innovation and circulation of the Bilateral Positioning Model. The model guarantees that consumers, merchants, and platforms interact, emphasizing the consumer experience and adding weight to their feedback.

Specifically, there is much chaos in the e-commerce industry, damaging consumers' right to know. With the intervention of third-party e-commerce platforms, merchants' behaviors can be effectively restrained by rewarding, such as free traffic promotion, setting up exclusive coupons, and punishing, such as lowering their ranking and issuing public warnings. It would form a benign competition atmosphere and infuse vitality for the 
platform. The "intervention" encourages consumers to participate in the whole business process. From grasping the shopping bias data, to the expectation of consumers' true evaluation and reporting business misconduct, consumers and the platform has always been mutually beneficial.

The e-commerce platform will promote goods based on the consumer' s shopping preferences. In a perfectly competitive necessity market, for example, the consumer's buying behavior will be greatly influenced by others' evaluation because of the homogeneity of the product. Once detected, fake reviews can reduce customer perceived value before a purchase is made and cause a business to lose customer lifetime value after the purchase is completed and receive a bad review until the unprofitable business exits the platform. The premise of this case is that false reviews are exposed and products that do not meet expectations are given poor reviews, and this can not be done without the platform' s supervision and encouragement that consumers should be rewarded for their honest behavior to continue to provide the platform with real data. The Bilateral Positioning Model emphasizes not the survival of the fittest, but the precise matching of supply and demand. Exiting from the platform is not the only outcome for offending vendors. Potential vendors can change their business strategies and focus on improving their vertical ratings based on the performance reviews given by the platform through bench-marking until a balance can be struck between data authenticity and a virtuous circle.

\subsection{Sample Monitoring}

In Bilateral Location Mode, complete and valid user profile are provided by $\mathrm{C}$-end with big data including their detailed shopping preferences and ideas, guiding B end merchants to eliminate unnecessary sales process and product promotion, and conform more to customers' shopping expectations. The information of customers' shopping behaviors from various channels such as mobile devices and advertising on the $\mathrm{C}$ end will be collected and analyzed, so as to identify user characteristics, classify existing customers on the platform, and give clear label instructions for each category. Furthermore, the platform can analyze the shopping preferences of more potential customers, so as to find more customers. The customer-related data exported in this mode is helpful for businesses to carry out precise advertising and fine operation, thus reducing the waste of resources and realizing the precise docking of each supply and demand.

During the process of operation, in order to ensure the real-time validity of the data, it is necessary for the model to continuously detect and calculate the changing user samples. Consumer behavior is influenced by personal factors and environmental factors, such as the growth of consumers' psychological age, the change of lifestyle, and external factors such as social class and cultural trends. In other words, with the passage of time and the development of the industry, the user portrait is in a dynamic change. To obtain more accurate data, the platforms using Bilateral Location Model encourage active user participation to obtain a timely and effective evaluation, which can be used as a reference to improve the data development. At the same time, with the increase of the number of participating users, the samples tend to be rich and complete, so that more accurate user portraits can be made, and the future development direction based on the prediction work of existing data will be clearer. In the process of operation and development, the Bilateral Location Model constantly provides more accurate user portraits and plays a good guiding role for the supply behavior of B-end merchants.

\section{LIMITATIONS AND FURTHER RESEARCH}

The team studied big data, lean production, performance in the platform. The conclusion shows that the Bilateral Positioning Model is valid in the three theories. For directions not covered, the team will further increase the depth and breadth of the research. The team is composed of four undergraduate students, so the current theory is not deep enough. After obtaining more experience, the team will make up for the deficiency. Currently, the Bilateral Positioning Model has formed a system, but it has not been practiced on the real e-commerce platform. Only through real practice can the advantages and disadvantages of this model be brought into play. After the pattern is applied, the shortcomings and inapplicability in the pattern will be improved by the team to improve the efficiency of the model.

\section{CONCLUSION}

To sum up, the innovative Bilateral Positioning Model based on the $\mathrm{C} 2 \mathrm{~B}$ shopping model can enable customers to shop efficiently and safely, promote healthy competition among enterprises and stimulate innovation ability. Therefore, this model can bring more profits to the online shopping platform and form a three-in-one layout. The team used a systematic literature review to analyze the three elements of the $\mathrm{C} 2 \mathrm{~B}$ model in the Bilateral Positioning Model, namely big data, lean production, and platform, to verify the enthusiasm of the Bilateral Positioning Model. The team first explored the positive role of these elements in the $\mathrm{C} 2 \mathrm{~B}$ shopping model and then studied the positive impact of the overall Bilateral Positioning Model. The team concluded that with effective supervision and operation, the Bilateral Positioning Model can promote the upgrading of the client, the merchant, and the platform. 


\section{REFERENCES}

[1] E.Turban, J. Whiteside, D. King, J. Outland, Introduction to Electronic Commerce and Social Commerce (4th ed.), Springer International Publishing, 2017, DOI: https://doi.org/10.1007/978-3-319-50091-1

[2] X. Zhang, X. Ming, Z. Liu, Y. Qu, D. Yin, State-of-the-art review of customer to business (C2B) model, Computers \& Industrial Engineering, 2019, pp. 207-222. DOI:10.1016/j.cie.2019.04.039

[3] M. Iguchi, M. Terada,Y. Nakamura, K. Fujimura, A voucher-integrated trading model for $\mathrm{C} 2 \mathrm{~B}$ and $\mathrm{C} 2 \mathrm{C}$ E-commerce system development, US: Springer, 2003.

[4] L. Witell, C. Kowalkowski, H. Perks, C. Raddats, M. Schwabe, O. Benedettini, J. Burton, Characterizing customer experience management in business markets, Journal of Business Research, 2020, pp. 420-430. DOI:10.1016/j.jbusres.2019.08.050

[5] T. Le, S. Liaw, Effects of Pros and Cons of Applying Big Data Analytics to Consumers' Responses in an E-Commerce Context, Sustainability, vol. 9, 2017, pp. 798-798. DOI: 10.3390/su9050798

[6] A. Cooper, The inmates are running the asylum, Indianapolis, 2015. G.S. Day, The capabilities of market-driven organizations, Journal of Marketing, vol. 58, 1994, pp. 37-52.

[7] D. Kostusev, Council post: Leveraging big data to model an IDEAL Buyer's persona, 2018

[8] H. Haans, N. Raassens, R.V. Hout, Search engine advertisements: The impact of advertising statements on click-through and conversion rates, Marketing Letters, Vol. 24, 2013, pp. 151-163. DOI: https://doi.org/10.1007/s11002-013-9226-5

[9] X. Xu, X. Wang, Y. Li, M. Haghighi, Business intelligence in online customer textual reviews: Understanding consumer perceptions and influential factors, 2017, DOI: 10.1016/j.ijinfomgt.2017.06.004

[10] A. Sana, G. Sumee, Customer perception of the deceptiveness of online product reviews: A speech act theory perspective, International Journal of Information Management, 2021, DOI: 10.1016/J.IJINFOMGT.2020.102286

[11] X. Zhang, X. Ming, Z. Liu, M. Zheng, Y. Qu, A new customization model for enterprises based on improved framework of customer to business: A case study in automobile industry, Advances in Mechanical Engineering, vol. 11, 2019.
[12] J.D. Reis, P. Neto, J. Fusco, S. Machado, Supply Chain Strategies in the Context of An E-commerce Chain (E-chain), Independent Journal of Management \& Production, vol. 5, 2014, pp. 438-457.

[13] C. Hill, T. Hult, International business: competing in the global marketplace (12th ed.), McGraw-Hill Education Publishing, 2017.

[14] R. Fu, L. Qin, Y. Gao, Study on the E-commerce platform based on the agent, Proceedings of SPIE, vol. 8205, 2011, DOI: https://doi.org/10.1117/12.905964

[15] X. Wan, J. Chen, J. Chen, The relationship between platform choice and supplier's efficiency- evidence from China's online to offline $(\mathrm{O} 2 \mathrm{O})$ e-commerce platforms, Electronic Markets, vol. 29, 2019, pp. 153-166. DOI: https://doi.org/10.1007/s12525-017-0280-3

[16] Z. Chen, J. Chen, Z. Zhang, Z, X. Zhi, Does network governance based on banks' e-commerce platform facilitate supply chain financing, China Agricultural Economic Review, vol. 11, 2019, pp. 688-703. DOI:

http://dx.doi.org.proxy.libraries.rutgers.edu/10.1108 /CAER-06-2018-0132

[17] M. Khouja, X. Liu, A Retailer's Decision to Join a Promotional Event of an E-commerce Platform, International Journal of Electronic Commerce, vol. 24, 2020, pp. 184-210. DOI: https://doi.org/10.1080/10864415.2020.1715529

[18] R. Varadarajan, Customer information resources advantage, marketing strategy and business performance: A market resources based view, Industrial Marketing Management, vol. 89, 2020, pp. 89-97. DOI:10.1016/j.indmarman.2020.03.003

[19] T. Keiningham,L. Aksoy, H.L. Bruce, F. Cadet, N. Clennell, I.R. Hodgkinson,T. Kearney, Customer experience driven business model innovation, Journal of Business Research, vol. 116, 2020, pp. 431-440. DOI: 10.1016/j.jbusres.2019.08.003

[20] E. J. Zajac, M. S. Kraatz, R. K. Bresser, Modeling the dynamics of strategic fifit: A normative approach to strategic change, Strategic Management Journal, vol. 21, 2000, pp. 429-453.

[21] F. Gedikli, D. Jannach, M. Ge, How should I explain A comparison of different explanation types for recommender systems, Bundeswehr University Munich, 2013, DOI: https.//doi.org/10.1016/j/ijhcs.2013.12.007

[22] X. Li, C. Wang, J. Tan, X. Zeng, D. Ou, B. Zheng, Adversarial Multimodal Representation Learning 
for Click-Through Rate Prediction, Proceedings of The Web Conference 2020, 2020, pp. 827-836. DOI: https://doi.org/10.1145/3366423.3380163

[23] L. Chen, W. Li, The Application of User Portrait Based on Big Data Analysis in Industrial Design Teaching, E3S Web of Conferences, vol. 179, 2020. 